\title{
Learning within sustainable educational innovation: An analysis of teachers' perceptions and leadership practice
}

\author{
G. M. Fix ${ }^{1,5} \cdot$ M. Rikkerink ${ }^{2}$ - H. T. M. Ritzen ${ }^{2}$ J. M. Pieters ${ }^{3}$ - W. A. J. M. Kuiper ${ }^{4}$
}

Accepted: 24 October 2020 / Published online: 8 December 2020

(C) The Author(s) 2020

\begin{abstract}
Innovative initiatives in education often have problems with their sustainability. The present study focuses on three educational innovations that have proved to be sustainable over time. We used a qualitative research approach to study and identify essential features of sustainable educational innovation. Two theoretical frameworks were used to guide the study: the integrated model for sustainable innovation (IMSI) and self-determination theory (SDT). Both frameworks take a different perspective upon learning; IMSI presents learning at the individual level, the team level and the organizational level to be the heart of sustainable innovation, and SDT presents how learning can be improved. The research question focused upon how the SDT concepts of autonomy, competence and relatedness were perceived within sustainable innovation, expressed by the IMSI framework, by teachers and school leaders. Based on our findings we demonstrate that the framework of IMSI and SDT can effectively be applied as a frame of analysis to identify essential features of sustainability in educational innovations and we discuss how concepts of SDT deepen the knowledge of sustainable educational innovation.
\end{abstract}

Keywords Sustainable educational change - Innovation in vocational education . Self-determination theory $\cdot$ Integrated model for sustainable innovation

G. M. Fix

g.m.fix@rug.nl; mfix@landstede.nl

1 Faculty of Behavioral and Social Science, University of Groningen, Groningen, The Netherlands

2 Saxion University of Applied Science, Enschede, The Netherlands

3 Faculty of Behavioral Science, University of Twente, Enschede, The Netherlands

4 Faculty of Science, Utrecht University, Utrecht, The Netherlands

5 Rechterland 1, 8024 AH Zwolle, The Netherlands 


\section{Introduction}

Innovations in educational contexts all over the world have problems with their sustainability (Adelman and Taylor 2014; Meki Kombe and Herman 2017) and there are many examples of innovations that are intensively developed, flourish for a while and then slowly disappear in the everyday hustle and bustle of the school. Based on the work of Rogers (2003), sustainability can be seen as a process of institutionalization in which the educational innovation must be spread over the organization. Rogers (2003) attributed a crucial role to human capital in the process of institutionalization, expressed by the commitment to the innovation of all of the participants, the teachers on the one hand and the school leaders on the other. This commitment is an important part of sustainability, because innovation often comes with new learning goals, learning activities or pedagogies and its success depends on the teachers' willingness to collaboratively change and adapt their practices (Kirschner et al. 2004; Thijs and Van den Akker 2009; Pieters et al. 2019). According to Rogers (2003), innovation occurs through adoption of the new ideas by the members of the social system within the innovation. The process is also reflected in the term 'learning organization', which represents the change in individuals and teams as result of learning that is considered to be the nucleus of innovation (Crossan et al. 1999). Because sustainable innovation depends on the learning of (groups of) individuals, it is of interest to investigate in depth how learning occurs in practice within the context of sustainable innovation and what benefits the individual learning process. The present study focuses on the analysis of essential effective characteristics of three educational innovations that have proved to be sustainable over time (Fix 2018; Fix et al. 2019). Because of this demonstrated sustainability these cases were worth studying and analyzing the essential features of sustainability. The three schools that participated in this study implemented an innovative new curriculum for students at risk of dropping out. The curriculum was aimed at supporting students in order to help them stay at school and leave with a diploma (Fix 2018).

\section{Theoretical framework}

We used two theoretical frameworks to guide the research for this study in order to analyze the characteristics of sustainability.. The first framework is known as the Integrated Model for Sustainable Innovation (IMSI, Fig. 1), based on the work of Rikkerink et al. (2016), and developed from models of learning in organizations (Crossan et al. 1999) and leadership practices (Spillane et al. 2004). IMSI provides four concepts that determine sustainable innovation in education, namely, distributed leadership, context-conscious leadership, vision and goals and flows of learning.

The second framework we used was originally developed to explain how individual learning can be improved, and is known as Self-Determination Theory 
Conceptual model of sustainable innovation

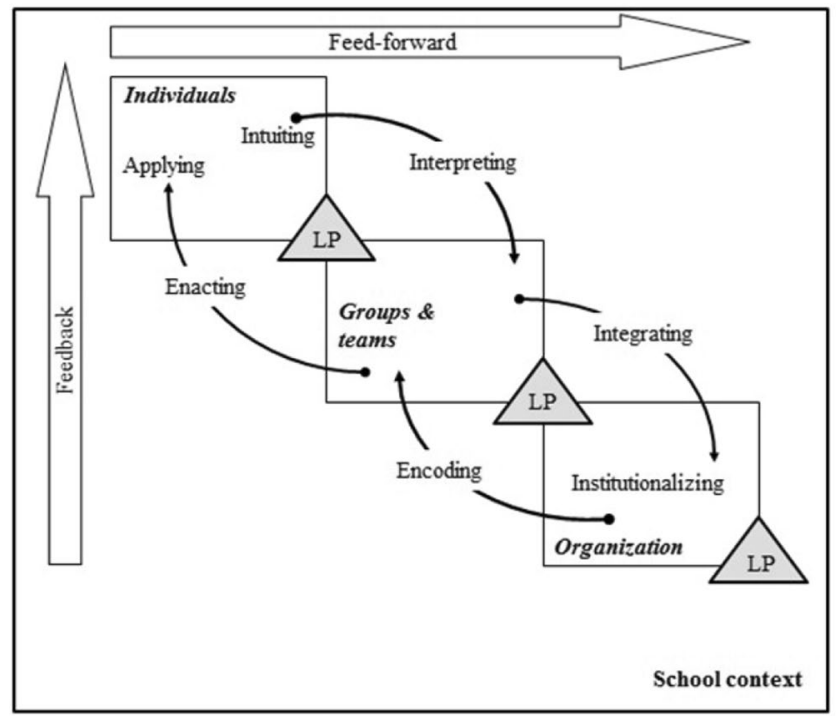

Auxiliary Figures

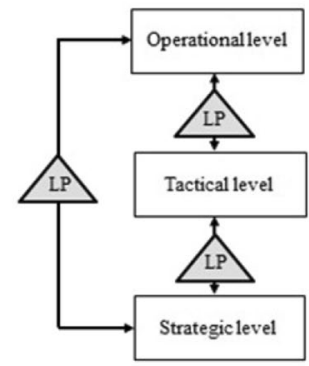

External context
pressure and

opportunities

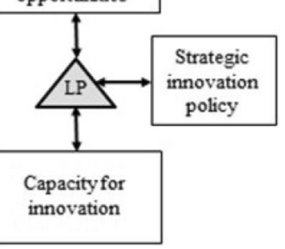

Fig. 1 Conceptual model of sustainable innovation (Rikkerink et al. 2016)

(SDT; Deci and Ryan 1985). SDT addresses three psychological needs, namely, the needs for autonomy, competence and relatedness. These needs contribute to self-regulated learning behavior and enhance feelings of interest and joy (Deci and Ryan 2000), which are strong predictors of job performance as well as perceived well-being (Deci et al. 2017; Ryan and Deci 2001). SDT was introduced in our study to amplify the meaning and relevance of the initial concepts of IMSI and to strengthen their expressiveness.

\section{Integrated model for sustainable innovation (IMSI)}

According to work by Spillane et al. (2004), leadership in educational practice is not allocated to a single person in the organization, but occurs at different levels of the school organization and can be formal as well as informal (distributed leadership). Rikkerink et al. (2016, p. 237) proposed that 'leadership practices' (LP) can be pictured as the interaction between the formal or informal leader, other actors and the situation, which characterizes the reciprocal interaction between the teacher, the school leader and the school environment. The innovating team of teachers cannot be defined as obedient followers; they have their own ideas, experiences and beliefs regarding the innovation. Leadership activities are therefore spread within the social context of the innovation and apply to formal as well as informal leaders (Rikkerink 2011; Rikkerink et al. 2016). 


\section{IMSI context-conscious leadership}

Settled standards and policy put pressure on the innovation, and the more an innovation plans to change, the bigger the environmental pressure (O'Hara et al. 1999). For successful innovation, this contextual influence must be managed and the amount of change must be carefully dosed (Kirschner et al. 2004). Rikkerink et al. (2016) demonstrated that the amount of change must be adapted to the innovative capacity of the team. This context-conscious leadership creates a balance between strategic leadership decisions, policy such as goals or vision, and teacher characteristics, including teachers' emotions and competences. Moreover, IMSI assumes the school leader must direct the process of innovation in line with existing policy and protect the team from too much information and contextual pressure (Rikkerink 2011; Rikkerink et al. 2016).

\section{IMSI vision and goals}

For sustainable innovation, school leaders at different levels of the organization must communicate with each other and pursue the same goals (Rikkerink 2011; Rikkerink et al. 2016). IMSI considers clear goal-setting at all levels of the organization to be an important determinant for the performance of the innovating team of teachers. Goals provide the innovating teams with clearer direction and allow them to determine better procedures and tasks; goals also bring focus to their effort to get the job done. Furthermore, goal achievement is facilitated by the social structure of the innovating team, which from the perspective of distributed leadership applies to all levels of the organization.

\section{IMSI flows of learning}

An important point of IMSI is that the learning processes of teachers are considered to be the backbone of educational innovation (Crossan et al. 1999; Rikkerink et al. 2016). This includes, in the first place, teachers' individual sensemaking with regard to new practices, as they attempt to fit the innovation into their existing beliefs and experience (Spillane et al. 2004). In addition, for sustainability, the innovation also requires collective sense-making by teachers and school leaders, for example, by sharing their thoughts, discussion and collective reflection (Rikkerink et al. 2016). This sense-making is of significant importance for the change that comes along with innovation, and is defined in IMSI as flows of learning. Individual and collective sense-making drive people to explore new practices (feed-forward flow of learning) and reflect upon or evaluate their practice (feedback flow of learning) as innovations are implemented in existing learning environments (Crossan et al. 1999). In these learning environments, stakeholders such as parents, students and colleagues have developed expectations, for example, concerning students' achievement. During the development of new 
practices, the innovating team must make sure to meet the expectations of the other stakeholders.

\section{Self-determination theory (SDT)}

To be able to explore flows of learning and the other IMSI concepts in greater depth, we used a framework that was developed to explain how individual learning can be improved, known as Self-Determination Theory (SDT; Deci and Ryan 1985). SDT addresses three psychological needs, namely, the needs for autonomy, competence and relatedness. According to SDT, perceived feelings of autonomy, competence and relatedness are important for people's learning process, foremost because they contribute to self-regulated learning behavior and enhance feelings of interest and joy (Deci and Ryan 2000), which are strong predictors of job performance as well as perceived well-being (Deci et al. 2017; Ryan and Deci 2001). SDT implies that teachers' learning is stimulated by support of teachers' perceived autonomy, which applies to opportunities to bring in their own ideas, opinions and personal experiences. In addition, feelings of autonomy also include the experience of being respected (Deci and Ryan 2000), addressing the social context in which autonomous action is embedded. Teachers' perceived autonomy in innovation leaves an important role for school leaders, for example, as they make sure teachers feel safe to change their individual ideas and respect the identities of individual teachers.

During innovation, teachers are challenged to develop new practices, directed by the innovation goals and stakeholder expectations. For teachers and school leaders, this includes learning goals for students as well as personal goals and organizational goals. The opportunity to contribute successfully to meeting goals and standards comes along with feelings of competence, which are driven by people's desire to achieve goals and standards that are important to them (Deci and Ryan 2000). Teachers reflect on how their personal goals, experiences and values fit with the innovation goals. Initiatives that have puzzling or trivial goals may hinder effective competence development if teachers struggle to match these goals with their personal experiences, values and goals.

SDT addresses the social aspect within learning as relatedness, which addresses the need for people to connect with other people. Different types of relationships may evoke feelings of relatedness for teachers, for example, in their relationships with colleagues, but perceived relatedness may also be present in teachers' contact with students. SDT considers perceived relatedness to occur primarily in caring and safe relationships where teachers can share ideas and feelings with others (Deci and Ryan 2000). SDT has been used to investigate motivation for learning in education (Haerens et al. 2015; Stroet et al. 2015; Van den Berghe et al. 2016).

The frameworks that guided our study do not exclusively address learning and innovation; however, the frameworks were chosen for specific reasons. The IMSI model was developed within one particular educational context (Rikkerink et al. 2016) and we wanted to explore whether the four IMSI concepts, distributed leadership, context-conscious leadership, vision and goals and flows of learning, are applicable to other sustainable educational contexts. Moreover, we wanted to explore how 
the SDT concepts, autonomy, competence and relatedness (Deci and Ryan 2000), may deepen the model of sustainable innovation with regard to the individual and group learning that we assume to be the heart of innovation. The SDT framework was chosen because in practice, the innovative curriculum for students was developed based on the SDT concepts (Fix 2018; Fix et al. 2019). We explored whether the three innovative practices as perceived by the innovating team of professionals (in this case, teachers and school leaders) also embraced the concepts of autonomy, competence and relatedness. Our research was aimed at exploration and strengthening in depth of a relatively new model (IMSI) and we addressed the following research question:

In what way do the concepts of autonomy, competence and relatedness contribute to the concepts of sustainable educational innovation in order to more thoroughly explain perceptions by teachers and school leaders?

\section{Methods}

\section{Context of the study}

In the Netherlands, students enroll higher education after primary and secondary education. A part of the students choose a vocational education track, they are educated for example for health care, ICT and construction work. Vocational tracks have different levels and students can archive several diplomas and certificates by climbing up within the educational system. However, not all students are feeling happy in this system, at the lowest levels of vocational education some students struggle to persist, they are at risk of leaving school without qualification.

Three different vocational educational centers (VET) in The Netherlands participated in this study, these schools all implemented a particular innovation, namely, a special curriculum to support students at risk within their own institution (Fix 2018). Students followed the supportive curriculum for ten weeks (instead of normal lessons), and after this participation the students continued with their regular education. Six years after implementing the innovative curriculum, the innovating teams at the schools were asked to join the present study. For school A, the team consisted of the school leader and four teachers. For school B, the team consisted of the school leader and two teachers, and for school $\mathrm{C}$ the school leader and one teacher participated. All participants were involved during the phases of design, trying out and implementation of the innovation.

\section{Data collection}

Data were collected in two different ways. First, a total of six semi-structured interviews were held, two at each participating school. One interview was held with the innovating team of teachers $(n=4$ at school $\mathrm{A}, n=2$ at school $\mathrm{B}$, and $n=1$ at school C) and one interview was held with the school leader of the innovating team. 
Table 1 Example of conceptual description and questions for teachers and school leaders

\section{Description: flows of learning}

During implementation of the new curriculum, a new concept entered the school. An important characteristic of this curriculum is personalized learning that stimulates students' perceived feelings of autonomy, competence and relationship. Stakeholders such as students and parents expect the innovative curriculum to guarantee student achievement, yet the innovating team developed a new curriculum including new goals, pedagogical approaches and learning activities. Feedback (guaranteeing results) and feed forward (exploring new practices) flows of learning may cause friction, but should be well balanced in order to strengthen both processes

Questions for teachers

During implementation of the new curriculum you carried out new practices; in the meanwhile, students' achievement had to be guaranteed. Did you perceive friction from that in your work?

How were the processes of innovation, renewal and improvement shaped during implementation of the new curriculum? How did you, as a teacher, perceive your own role in this and the role of your school leader?

How were the processes of evaluation, feedback and sense-making shaped to guarantee students' achievement? How did you, as a teacher, perceive your own role in this and the role of your school leader?

Questions for school leaders

During implementation of the new curriculum, your team of teachers developed new practices; in the meanwhile, students' achievement had to be guaranteed. Did you perceive friction from that while managing the innovation?

How did you manage processes of innovation, renewing and improvement shaped during implementation of the new curriculum? How did you perceive your own role in this and the role of your team?

How did you manage the processes of evaluation, feedback and sense-making shaped to guarantee students' achievement? How did you perceive your own role in this and the role of your team?

Each interview took about one hour and a half. Before the interview, the participants were informed about the goal of the study and gave permission to record the interview and for anonymized use of the information.

Interview questions were aimed at exploring how the IMSI concepts, distributed leadership, context-conscious leadership, vision and goals, and flows of learning, were recognized in practice by the teachers and school leaders. Because the participants were not familiar with the IMSI concepts, we used supportive descriptions to clarify the four IMSI concepts (see Table 1 for an example) and to ensure that the participants interpreted the concepts similarly. The supportive descriptions were constructed together with the researcher who developed the IMSI model (Rikkerink et al. 2016) and discussed with teachers who did not participate the study in order to make sure the descriptions were clear and understandable. We made some textual modifications, but no radical adjustments were necessary.

Before the interview started, the participants were asked to read the description of the first concept (distributed leadership) and could ask clarifying questions. After the concept was clear, the participants responded to the interview questions belonging to that concept. Subsequently the participants read the description of the second concept (context-conscious leadership), again could ask clarifying questions, and then responded to the interview questions; this proceeded until the participants had responded to all of the interview questions (see Table 1 for examples of the interview questions). 
Interview questions for the teachers and the school leaders were both focused upon the IMSI concepts; however, the questions differed slightly because they had different responsibilities and tasks within the innovation (see Table 1).

Interview questions did not explicitly include questions about the SDT concepts of autonomy, competence and relatedness; these concepts were latent and exclusively meant to further analyze the data for their impact within the IMSI framework.

The interviews were transcribed and anonymized; to strengthen construct validity, we asked the participants to read, supplement and correct the transcripts. Two interviewees (both school leaders) asked for adjustments, which was because they wanted to nuance their words or add an explanation of their words. After the adjustments were made, both agreed with the content, and we included their interviews in the database.

Second, a document study was conducted to investigate one IMSI concept, namely, the (described) vision and goals. The other IMSI concepts (flows of learning, context-conscious leadership and distributed leadership) applied to innovative processes and were not expected to be present in documents. The innovating teams were asked for relevant documents that described the innovative curriculum, including its goals and vision. A total of 35 documents associated with the innovation were collected. The schools collaboratively designed developed and implemented the curriculum; therefore, 11 documents were connected to a specific school while 24 documents applied to all schools (Table 2).

\section{Data analysis}

Data were analyzed by the head researcher (the first author) using the software program Atlas.ti. To enhance reliability, she worked together with an expert in the field of school innovation and leadership (the second author). The researchers went through a series of analytic steps.

First, analysis was done using a deductive approach. The head researcher searched the data for themes established in advance that were connected to the IMSI concepts: distributed leadership, context-conscious leadership, flows of learning and vision and goals. Data that were determined to be relevant were coded. The concepts

Table 2 Overview of collected documents for every school

\begin{tabular}{llc}
\hline School & Type of document & Number \\
\hline School A & Program description & 1 \\
& Research report & 1 \\
School B & Program description & 1 \\
& Research report & 3 \\
School C & Program description & 1 \\
& Research reports & 4 \\
Project documents applying & Meeting notes & 10 \\
to all schools & Project reports & 5 \\
& Other & 9 \\
\hline
\end{tabular}


of IMSI are closely interconnected, and therefore a phrase could be coded more than once, for example, as distributed leadership and flow of learning. The coded data were discussed with the second author, first to check if the data fragments were correctly labeled, and second to determine principal themes for the concepts of sustainable innovation as perceived by the innovating team.

Next, in order to deepen the knowledge of IMSI, all data were again analyzed by the head researcher using the same deductive approach; however, this time a different coding frame was used, based on the SDT concepts, autonomy, competence and relatedness. The coded data were again discussed with the second author, to check if the data fragments were correctly labeled and also determine principal themes for the SDT concepts.

After that, we selected the data that were recognized by the researchers both as an IMSI and as a SDT concept. The researchers discussed how the concepts of autonomy, competence and relatedness were perceived within the concepts of sustainable innovation: distributed leadership, context-conscious leadership, vision and goals and flows of learning.

\section{Results}

We researched how the SDT concepts were perceived within the IMSI concepts by teachers and school leaders and these concepts were further analyzed to identify their relevance for IMSI. First, we present how autonomy was perceived within the IMSI concepts, followed by the results for competence and then the results for relatedness.

\section{Autonomy within the concepts of sustainable innovation}

In this study the concept of autonomy was perceived by all teachers within the concept of distributed leadership. Teachers experienced that they could autonomously shape their practice as long as they worked on program goals. The teachers had to report to their school leader about their choices, but they could freely develop their pedagogical approach and design appropriate learning activities. They experienced no controlling behavior by their school leader and perceived trust from their school leader and respect for their individual personalities. The school leaders connected autonomy for teachers with flows of learning, because freedom caused discussion, self-reflection and perceived ownership. In addition, school leaders reported that the amount of autonomy that was given to the innovating teams very much depended on the teachers' expertise; good teachers meant more autonomy and less controlling behavior by the school leader.

All school leaders experienced autonomy in their jobs. They were accountable for the innovation at different levels of the organization; this accountability was primarily focused on the goals and finances. In addition, they were convinced that autonomy could only flourish if collective sense-making was part of distributed leadership practices and present at different levels of the organization. Too much 
autonomy led to little engagement in collective sense-making, which worked against sustainability of the innovation. At school B, the school leader mentioned that lack of collective sense-making at different levels of the organization was a serious threat for the future of the innovation.

Autonomous development of the innovation was part of the teachers' job, and teachers noted that they liked thinking about improvement and were always looking around for innovative ideas. They used their own networks for this, both within and outside the school, to bring in new ideas, for example, for learning activities or learning materials. The school leader's role at all schools was experienced primarily as being a facilitator, not as bringing in innovative ideas. Autonomous development of the innovation was perceived by the teachers and the school leaders within the concept of context-conscious leadership, as the contextual standards of the school imposed financial and organizational restrictions on the innovating team. On the other hand, the contextual restrictions helped the innovation to fit into the school system: "I fully agree that we have better structures now in our innovation, but it took some of my autonomy away from me" (teacher, school C).

\section{Competence within the concepts of sustainable innovation}

The teachers at all schools were focused upon reaching the goals, which they related to sustainability of the innovation: "If we reach the curricular goals, it will be okay at all the other levels of the organization" (teacher, school B). They were convinced that they had the competences needed to reach the goals. According to the school leaders, development of new practices called for special competences: "Not every teacher is able to do this" (school leader, school C). The school leaders noted that the teachers in the innovating teams had to develop their competences, because the innovation called for different goals and pedagogical approaches compared to regular educational practice. The school leaders also proposed that teachers' competence was related to the effectiveness of the innovation, and that it was their responsibility to facilitate competence development. The school leaders linked competence development to flows of learning, because teachers learned from the collective sensemaking and reflection on new practices that come with innovation.

The school leaders were convinced that distributed leadership contributed to the quality of the innovation; they posited that freedom for teachers' expertise led to an innovation that was very well adapted for students: "I think you have to leave that to the teachers, they are experts, they know what to do" (school leader, school C). The school leaders at schools A and B also referred to context-conscious leadership in relation to competence development. Traditional views of classroom learning may hinder teachers' competence development within their new practices, for example, because the effectiveness of the new practices is in doubt.

\section{Relatedness within the concepts of sustainable innovation}

All teachers as well as school leaders reported an open, supportive, fair and pleasant atmosphere in their relationships, which was related to the concept of flows of 
learning. Teachers experienced equality and respect and they felt safe sharing their feelings and opinions, even in discussions. Both teachers and school leaders tried to help each other's practice by providing ideas and feedback. In addition, at schools B and $\mathrm{C}$, the teachers and the school leaders mentioned that their positive relationships provided opportunities for flows of learning; however, in practice, they often did not take enough time for this.

Teachers experienced that supportive relationships can be threatened by expectations regarding academic achievement from colleagues, students, and sometimes parents (schools A and B). The teachers at school B perceived struggles to meet these expectations: "I was struggling with that also ... classes and tests are very easily measurable, and here I'm thinking, how do we know we reached the goal with a student" (teacher, school B). According to the school leader at school B, it takes time to experience new practices as effective.

Sometimes teachers experienced difficulties in relationships with colleagues; for example, because of a different vision (school A). The school leader at school A agreed that conflicts were sometimes part of collective sense-making, especially concerning vision and goals; she focused in her leadership practice on connecting the teachers and supporting them.

The school leaders emphasized the importance of positive relationships for collective sense-making at the vertical level of the organization. To keep the innovation successful in the future, all stakeholders had to be in contact with each other, discussing the vision and goals of the innovation. Lack of clarity about expected results led to disappointment and questions about the effectiveness of the innovation.

\section{Conclusions}

We used a qualitative research approach to study and identify essential features of a sustainable educational innovation. The research question focused upon how the SDT concepts of autonomy, competence and relatedness were perceived within sustainable innovation, expressed by the IMSI framework, by teachers and school leaders.

Based on the findings, we conclude that autonomy was perceived within distributed leadership, as teachers experienced that they could autonomously shape their practice and experienced trust and respect from their school leader. The school leaders proposed that autonomy for teachers was important for flows of learning, because autonomy determined self-reflection, perceived ownership and collective sense-making about vision and goals. In addition, the school leaders were convinced that autonomy could only flourish if flows of learning were present at all levels of the organization (distributed leadership). The degree of autonomy had to be well balanced; too much autonomy worked against sustainability of the innovation, according to the teachers and school leaders. Restrictions on autonomy were experienced within the concept of context-conscious leadership, as the contextual standards of the school imposed financial and organizational restrictions on the innovating teams.

Furthermore, school leaders posited that for sustainable innovation, teachers had to develop their competences, because the innovation called for new practices. 
School leaders linked competence development to flows of learning and were convinced that distributed leadership contributed to the quality of the innovation. The school leaders also proposed that competence development could be hindered, as teachers had doubt about effectiveness of the innovation, caused by their traditional beliefs and expectations. The teachers themselves did not mention competence development in relation to flows of learning.

The teachers as well as the school leaders reported positive relatedness to be important for flows of learning. At one school, the teachers and school leader experienced difficulties in relationships between team members during the process of collective sense-making, caused by different opinions about vision and goals. The school leaders also emphasized the importance of positive and supportive relationships for distributed leadership and flows of learning at the vertical level of the organization.

Our study demonstrated that the framework we conceived of IMSI and SDT can effectively be applied as a frame of analysis to identify essential features of sustainability in educational innovations.

\section{Discussion}

For the present study, we used two theoretical frameworks to guide our research. Both frameworks take a different perspective upon learning; IMSI presents learning at the individual level, the team level and the organizational level to be the heart of sustainable innovation (flows of learning), and SDT presents how learning on these levels can be improved. Based on our findings, we suggest that perceived autonomy strengthens flows of learning and that flows of learning stimulate teachers' competence development. We propose that this occurs at the level of the individual teacher, but also within innovating teams. Furthermore, we address the importance of positive relatedness between team members for flows of learning, especially with regard to collective sense-making and goal-setting. Based on our results, we assume that leadership practices play an important role in facilitating flows of learning, for example, because the school leaders give well-balanced autonomy to the teachers and create positive relatedness between team members. In addition, distributed leadership practices require positive relatedness between stakeholders at different levels of the organization in order to facilitate flows of learning within the organization. Figure 2 is a representation of how the concepts of autonomy, competence and relatedness can be represented in the integrated model of sustainable innovation with regard to flows of learning.

Despite all effort, research provides evidence that practitioners return to their old habits after the support for innovations are withdrawn (Hubers et al. 2017). The work of Hubers (2020a, b) and Rogers (2003) points out the importance for more knowledge on how deeper learning can be benefited in practice in order to refine and optimize professional development and together with that, sustainable educational change. Regarding this, opportunities for professional development might occur within the relatively new phenomena of professional learning communities (PLC). These communities are often aimed at improving educational 


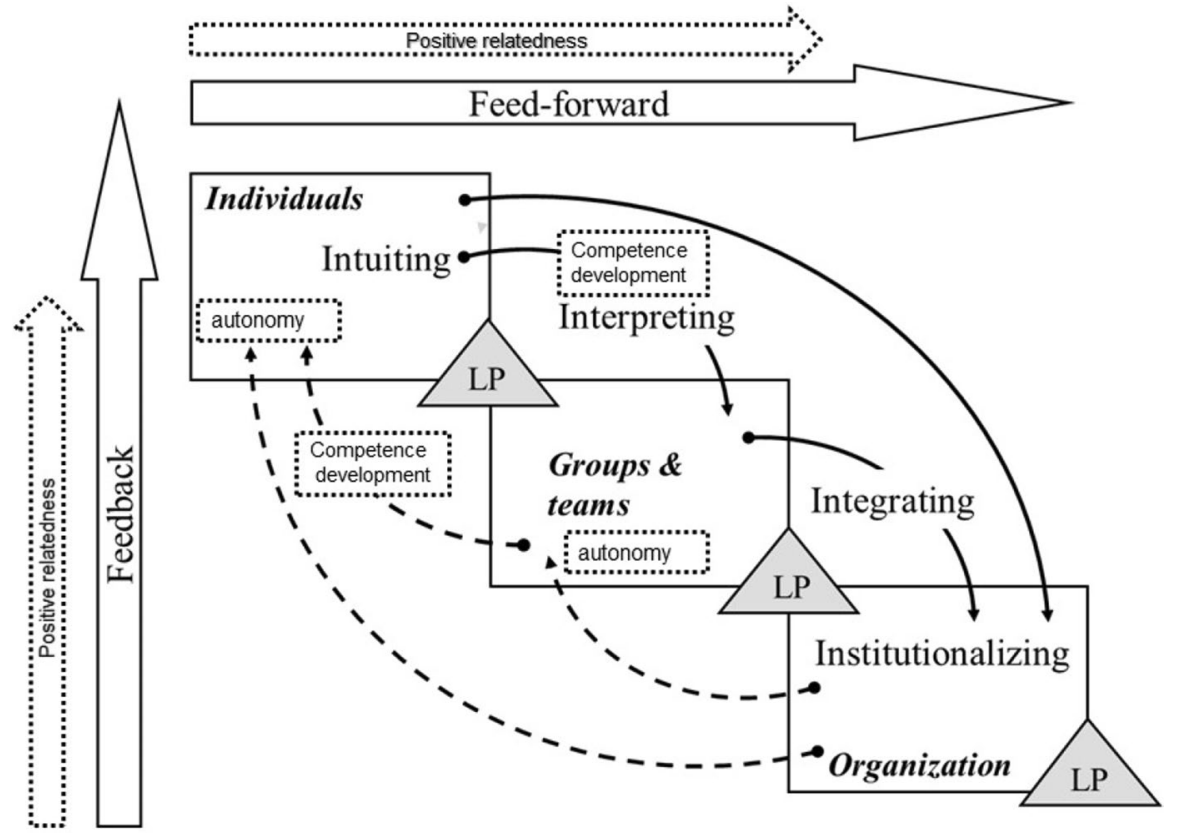

Fig. 2 Concepts of autonomy, competence and relatedness integrated in flows of learning in the conceptual model of sustainable innovation

practice and have two important characteristics that are closely connected to our findings, first learning within PLC takes place by interaction with other members of the community, in other words PLC members learn together and from each other. Secondly the learning occurs in a non-formal for example as people are able to decide what they want to learn and how they want to learn. Moreover, Boom-Muilenburg et al. (2020) explore on leadership practices within PLC, they argue that leadership is more integrated instead of formalized, which is also a starting point of IMSI.

We are aware that this study presents only preliminary conclusions, in the first place because our study was limited to the level of individuals and groups. Other research in the field of (educational) innovation that has been based on self-determination theory has also considered the level of individuals and teams (Klaeijsen et al. 2018; Mudambi et al. 2007; Schellenbach-Zell and Gräsel 2010). However, we know that for sustainability the innovation has to be institutionalized (Rikkerink 2011; Rikkerink et al. 2016; Rogers 2003), which suggests also the necessity for research from an organizational perspective. Self-determination theory has been used in organizational research (Sheldon et al. 2003), which has provided insight on supporting employees' motivation and well-being within organizations (Van den Broeck et al. 2016, 2019), but lacks information about the field of educational innovation. To better understand how concepts of autonomy, competence and relatedness are presented during the process of institutionalizing an educational innovation, more research that considers the organizational perspective more specifically is 
necessary, for example, on the concepts of context-conscious leadership and distributed leadership practices.

With our research we focused upon in-depth perspectives on sustainable innovation and because of the exploratory character of this study. We are convinced that this approach yielded valuable information however, we are aware of the limitations. In addition, we emphasize that our results are context-specific, which means that they must be interpreted within our research context, and that findings can only be transferred to other contexts with caution. In addition, future research using other methodological approaches may strengthen our findings and increase the generalizability of the results.

Open Access This article is licensed under a Creative Commons Attribution 4.0 International License, which permits use, sharing, adaptation, distribution and reproduction in any medium or format, as long as you give appropriate credit to the original author(s) and the source, provide a link to the Creative Commons licence, and indicate if changes were made. The images or other third party material in this article are included in the article's Creative Commons licence, unless indicated otherwise in a credit line to the material. If material is not included in the article's Creative Commons licence and your intended use is not permitted by statutory regulation or exceeds the permitted use, you will need to obtain permission directly from the copyright holder. To view a copy of this licence, visit http://creativecommons.org/licen ses/by/4.0/.

\section{References}

Adelman, H. S., \& Taylor, L. (2014). Embedding school health into school improvement policy. International Journal of School Health, 1(3), e24546.

Boom-Muilenburg, van den, E., Tappel, A., Schildkamp, K., \& Poortman, C. (2020). Duurzame onderwijsontwikkeling door professionele leergemeenschappen: Leiderschap als smaakmaker [sustainable educational change by professional learning communities: leadership as flavor]. School Management Totaal. https://www.utwente.nl/nl/bms/elan/duurzame-onderwijs-ontwikkeling/presentatiespublicaties/Presentaties-Opslag/ltr-p032-ltr-schoza-02-2020-002.pdf.

Crossan, M. M., Lane, H. W., \& White, R. E. (1999). An organizational learning framework: From intuition to institution. Academy of Management Review, 24(3), 522-537.

Deci, E. L., Olafsen, A. H., \& Ryan, R. M. (2017). Self-determination theory in work organizations: the state of a science. Annual Review of Organizational Psychology and Organizational Behavior, 4, $19-43$.

Deci, E., \& Ryan, R. M. (1985). Intrinsic motivation and self-determination in human behavior. New York: Plenum Press.

Deci, E. L., \& Ryan, R. M. (2000). The "what" and "why" of goal pursuits: Human needs and the selfdetermination of behavior. Psychological Inquiry, 11(4), 227-268.

Fix, G. M. (2018). The football stadium as classroom: Exploring a program for at-risk students in secondary vocational education. Doctoral dissertation. University of Twente, Enschede.

Fix, G. M., Ritzen, H. T. M., Pieters, J. M., \& Kuiper, W. A. J. M. (2019). Effective curricula for at-risk students in vocational education: A study of teachers' practice. Empirical Research in Vocational Education and Training, 11(1), 1.

Haerens, L., Aelterman, N., Vansteenkiste, M., Soenens, B., \& Van Petegem, S. (2015). Do perceived autonomy-supportive and controlling teaching relate to physical education students' motivational experiences through unique pathways? Distinguishing between the bright and dark side of motivation. Psychology of Sport and Exercise, 16, 26-36.

Hubers, M. D. (2020a). In pursuit of sustainable educational change-introduction to the special section. Teaching and Teacher Education, 93, 103084. https://doi.org/10.1016/j.tate.2020.103084. 
Hubers, M. D. (2020b). Paving the way for sustainable educational change: Reconceptualizing what it means to make educational changes that last. Teaching and Teacher Education, 93, 103083. https:// doi.org/10.1016/j.tate.2020.103083.

Hubers, M. D., Schildkamp, K., Poortman, C. L., \& Pieters, J. M. (2017). The quest for sustained data use: Developing organizational routines. Teaching and Teacher Education, 67, 509-521.

Kirschner, P. A., Hendriks, M., Paas, F., Wopereis, I., \& Cordewener, B. (2004). Determinants for failure and success of innovation projects: The road to sustainable educational innovation. In: Paper presented at the meeting of the association for educational communications and technology, Chicaco, IL.

Klaeijsen, A., Vermeulen, M., \& Martens, R. (2018). Teachers' innovative behaviour: The importance of basic psychological need satisfaction, intrinsic motivation, and occupational self-efficacy. Scandinavian Journal of Educational Research, 62(5), 769-782.

Meki Kombe, C. L., \& Herman, C. (2017). Can education innovations be sustained after the end of donor funding? The case of a reading intervention program in Zambia. Educational Review, 69(5), 533-553.

Mudambi, R., Mudambi, S. M., \& Navarra, P. (2007). Global innovation in MNCs: The effects of subsidiary self-determination and teamwork. Journal of Product Innovation Management, 24(5), 442-455.

O'Hara, M. T., Watson, R. T., \& Kavan, C. B. (1999). Managing the three levels of change. Information Systems Management, 16, 63-70.

Pieters, J. M., Voogt, J. M., \& Pareja Roblin, N. (Eds.). (2019). Collaborative curriculum design for sustainable innovation and teacher learning. Berlin: Springer.

Rikkerink, M. (2011). Invoering van een gedigitaliseerde onderwijspraktijk-Deel A: Patronen van interventies in een model van organisatieleren en leiderschapspraktijken [Implementation of a digital teaching practice. Part A. Pattern of interventions in a framework of organizational learning and leadership practices]. Doctoral dissertation. Utrecht University, Utrecht.

Rikkerink, M., Verbeeten, H., Simons, R. J., \& Ritzen, H. (2016). A new model of educational innovation: Exploring the nexus of organizational learning, distributed leadership, and digital technologies. Journal of Educational Change, 17(2), 223-249.

Rogers, E. M. (2003). The diffusion of innovation (5th ed.). New York: Simon \& Chuster.

Ryan, R. M., \& Deci, E. L. (2001). On happiness and human potentials: A review of research on hedonic and eudaimonic well-being. Annual Review of Psychology, 52(1), 141-166.

Schellenbach-Zell, J., \& Gräsel, C. (2010). Teacher motivation for participating in school innovationssupporting factors. Journal for Educational Research Online, 2(2), 34-54.

Sheldon, K. M., Turban, D. B., Brown, K. G., Barrick, M. R., \& Judge, T. A. (2003). Applying selfdetermination theory to organizational research. Research in Personnel and Human Resources Management, 22, 357-394.

Spillane, J. P., Halverson, R., \& Diamond, J. B. (2004). Towards a theory of leadership practice: A distributed perspective. Journal of Curriculum Studies, 36(1), 3-34.

Stroet, K. F. A., Opdenakker, M., \& Minnaert, A. (2015). Need-supportive teaching in practice: A narrative analysis in schools with contrasting educational approaches. Social Psychology of Education, $18(3), 585-613$.

Thijs, A., \& Van den Akker, J. (2009). Curriculum in development. Enschede: Stichting Leerplan Onderwijs.

Van den Berghe, L., Cardon, G., Tallir, I., Kirk, D., \& Haerens, L. (2016). Dynamics of need-supportive and need-thwarting teaching behavior: The bidirectional relationship with student engagement and disengagement in the beginning of a lesson. Physical Education and Sports Pedagogy, 21(6), 653-670.

Van den Broeck, A., Carpini, J., \& Diefendorff, J. (2019). Work motivation: Where do the different perspectives lead us. In R. Ryan (Ed.), The Oxford handbook of human motivation (2nd ed.). New York: The Oxford University Press.

Van den Broeck, A., Ferris, D. L., Chang, C. H., \& Rosen, C. C. (2016). A review of self-determination theory's basic psychological needs at work. Journal of Management, 42(5), 1195-1229.

Publisher's Note Springer Nature remains neutral with regard to jurisdictional claims in published maps and institutional affiliations. 